\title{
Increasing the Appeal of Neurosurgery to Qualified Medical Students in Canada
}

\author{
Mitchell P. Wilson, Jeffrey A. Pugh
}

Can J Neurol Sci. 2012; 39: 667-669

The education climate in Canadian medical schools has changed dramatically over the past ten years. A growing and aging population has demanded significant increases in medical school enrollment, with a focus on producing primary care physicians. Despite doubling the number of graduating medical students during this time (Figure 1), the number of candidates applying to Neurosurgery has remained relatively stable. These statistics are concerning when considering five of the past ten years have seen less students rank Neurosurgery as a first choice discipline than the number of Residency positions available, though the overall match rate has remained 1:1 (Figure 2) ${ }^{1}$. Based on current trends, it is possible that Neurosurgery is failing to appeal to and attract qualified applicants who may otherwise consider a career in this field. This may be inherently limiting the selection process for Neurosurgical programs across the country to only a small cohort of students. Inconsistencies between an increasing number of medical students but relatively stable number of Neurosurgery applicants could be due to both changing student priorities in medical and surgical careers as well as decreased exposure to Neurosurgery in the face of a changing medical curriculum. Both factors should be addressed in order to ensure students well suited for Neurosurgery continue to apply.

As of 2010, balance between work and personal life and obtaining sufficient medical competence were cited as the two most important factors for Canadian medical students in determining a satisfying and successful career ${ }^{2}$. As student priorities continue to change, it is possible students have ruled out Neurosurgery on the basis of expected lifestyle and content difficulty prior to adequate exposure and knowledge of the specialty. Ironically, in the same National Physician Survey, Neurosurgeons report the highest percent of satisfaction compared to all surgical specialties when it comes to balance between personal and professional commitments. Of all respondents, $64.7 \%$ were somewhat or very satisfied with this component of their life. In addition, they had comparable results to other competitive surgical specialties when addressing satisfaction of their professional life. It may be beneficial to address student concerns early in training regarding lifestyle and content difficulty, as well as other factors considered important to medical students today, including length of training, job prospects, daily activity, financial remuneration, patient demographics, and the expectations of a Neurosurgical career.

Students may also fail to experience adequate exposure to Neurosurgery during their training. In a recent survey of medical students, few agreed that they had a good understanding of the Neurosurgical specialty ${ }^{3}$. This is especially true for students undergoing their formative pre-clinical years where
Neurosurgery has become relatively limited in recent history, as an emphasis on primary care has changed the objectives of undergraduate medical education ${ }^{4}$. Considering $80 \%$ of students who choose surgery as a career have done so by their second year of medical school, with over $23 \%$ of these students deciding on their specialty by this time, this may be leading students to rule out Neurosurgery based purely on inadequate exposure or awareness 5 .

In addition, the disparity between the proportion of female medical students graduating from Canadian medical schools and proportion of female applicants selecting surgical specialties has likely affected application rates. This has recently been addressed by the Board of Directors of the AANS as a particular concern in Neurosurgery ${ }^{6}$. In the 2011 CaRMS match, women comprised almost $60 \%$ of participating graduates but only $25 \%$ of those ranking Neurosurgery as their first choice; a sentiment which has been mimicked for the past ten years (Figure 3$)^{1}$. While there appears to be a trend towards increased application rates, a clear difference between the percentages of females in the CaRMS match and those applying to Neurosurgery still exists. Benzil et al have suggested that concerns of gender inequalities such as acceptance to the residency, promotion, and achieving leadership positions have been potential obstacles for women considering a career in Neurosurgery ${ }^{6}$. They also note that having fewer female academic neurosurgeons to act as same gendered role models may inherently decrease the number of female applicants. The progressive increase in female medical students graduating from Canadian medical schools demands specific consideration in order to address disparities in application rates.

Several suggestions to address changing medical student priorities and curriculum exposure for surgical specialties have been made in the past (Table $)^{7-9}$. In particular, early exposure as well as mentorship that emphasizes the positive aspects of the specialty have been found to be strongly associated with student choices of surgical specialties ${ }^{10-11}$. Ensuring Neurosurgery staff and residents have a presence in the pre-clinical years through both an increased role inside and outside the classroom is

From the Faculty of Medicine and Dentistry (MPW); Division of Neurosurgery, Department of Surgery and Clinical Department of Neurosciences (JAP), University of Alberta, Edmonton, Alberta, Canada.

Received September 7, 2011. Final Revisions Submitted March 15, 2012. Correspondence to: Mitchell P. Wilson, 2C3.74 MHSC 8440-112 Street, University of Alberta, Edmonton, Alberta, T6G2B7, Canada. Email: mitch.wilson@ualberta.ca. 


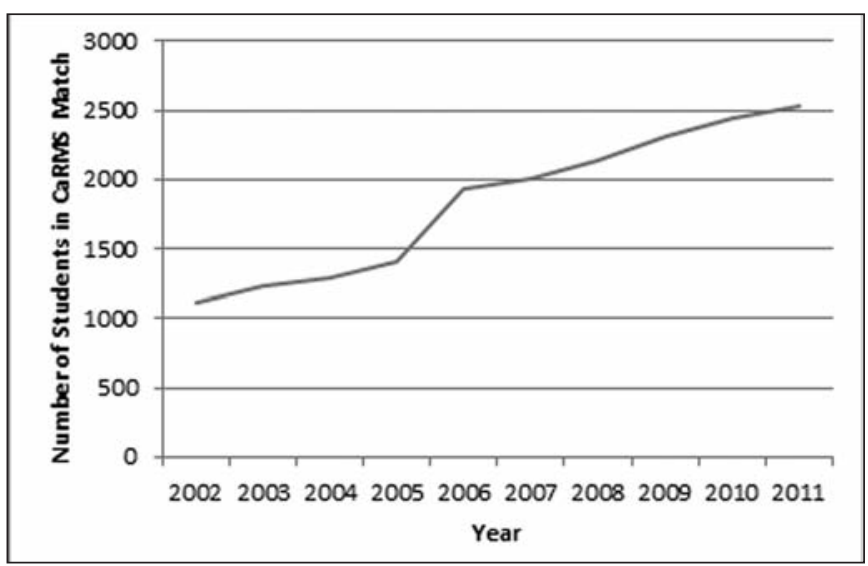

Figure 1: Canadian Resident Matching Service total number of students in the CaRMS match from 2002-2011 ${ }^{\text {. }}$.

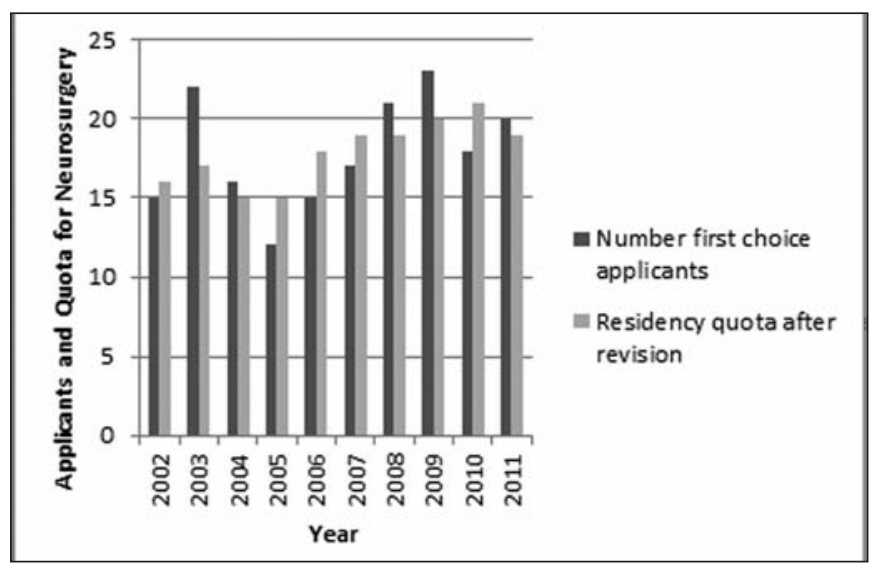

Figure 2: Canadian Resident Matching Service number of first choice applicants and quota of residency position per year from 2002-2011 ${ }^{1}$.

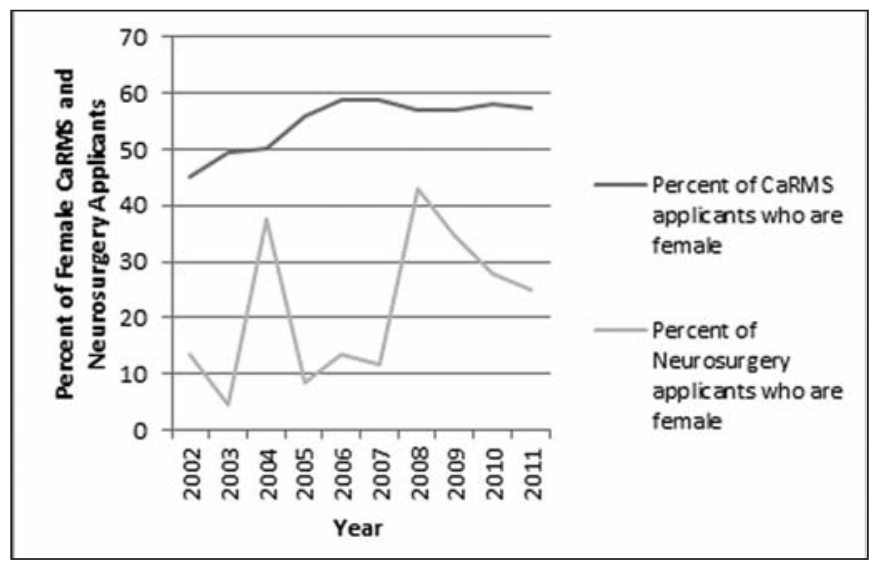

Figure 3: Canadian Resident Matching Service percentages of CaRMS applicants and first choice Neurosurgery applicants who are female from 2002-2011

Table: Recommendations to increase awareness and appeal of Neurosurgery to medical students ${ }^{7-9}$.

Establish a Mentorship Program

Promote positive mentorship starting early in training and lasting throughout a medical students' education.

Ensure exposure during pre-clinical content

Involve neurosurgical staff and residents in teaching components of the pre-clinical curriculum including lecture content and clinical skills.

Establish a Summer Research Program

Establish a Neurosurgery summer research program for medical students during their pre-clinical years.

Establish an Interest Group in Neurosurgery

Establish interest groups that teach students about clerkship, residency, fellowships and careers as well as skills such as suturing. Provide tours of the operating rooms and surgical environments.

Provide talks on Neurosurgery

Provide talks early in medical students' training addressing answers to concerns regarding the specialty. Lifestyles of residents and staff should be emphasized while content difficulty, length of training, job prospects, daily activity, financial remuneration, patient demographics, and the expectations of a Neurosurgical career should be covered as well. Talks specialized to addressing female concerns such as maternity leave should be provided.

Provide positive shadowing and elective experiences

Provide positive shadowing and elective experiences with focus on acquiring clinical and operative skills. Students should be exposed to and involved with all aspects of a Neurosurgeons' daily activity.

Establish a website

Establish a website that provides easy access to opportunities within the field for medical students. 
necessary. Providing talks during students' formative years addressing factors important to medical students may serve as an easy way to dispel potential myths of a Neurosurgical career. A focused effort should also be made to better accommodate and encourage female applicants. Connecting students with samegendered mentors and talks directly addressing concerns of gender disparities may help. Models of aggressive recruitment to both Neurological and Cardiothoracic surgery through research, shadowing, and mentorship opportunities during the students' formative years have shown to be successful at Johns' Hopkins Medical School ${ }^{12-13}$. These simple steps taken to increase positive exposure for students have increased the number of students applying for, and successfully entering residency positions in their respective specialties.

There remains debate regarding the number of Neurosurgeons needed to treat the Canadian population. Currently, the ratio of Neurosurgeons to citizens in Canada is about 1:159000 with a benchmark of $1: 129500^{14}$. Given the current workforce and future demand, the need for Neurosurgeons in Canada will at least maintain but likely increase. Though some argue that too many Residents are currently being trained with only $45 \%$ of graduates finding work in Canada upon completion ${ }^{14}$, Neurosurgery continues to be an underserviced specialty in Canada and the numbers provided by this group may be complicated by several logistical and systemic issues ${ }^{15}$. Overall, the best approach to ensuring residency positions in Canada are filled with the most appropriate candidates is to ensure these students are exposed early, with specific recognition of student priorities and gender inequalities. By eliminating unnecessary deterrents and applying models shown to be successful in the United States, we can ensure Neurosurgery residency programs in Canada remain filled with highly capable applicants.

\section{REFERENCES}

1. Canadian Resident Matching Service [Internet]. Ottawa; CaRMS; c2002-2011 [updated 2011 April 20; cited 2011 December 20]. Operations reports and statistics. Available from: http://www. carms.ca/eng/operations_R1reports_e.shtml.

2. National Physician Survey [Internet]. Mississauga: NPS; C20062011 [updated 2011 December 2; cited 2011 December 20]. 2010 medical student results. Available from: http://www.national physiciansurvey.ca/nps/2010_Survey/2010results-e.asp.

3. Hill CS, Dias L, Kitchen N. Perceptions of neurosurgery: a survey of medical students and foundation doctors. Br J Neurosurg. 2011;25(2):261-7.

4. Resnick DK. Neuroscience education of undergraduate medical students. Part I: role of neurosurgeons as educators. J Neurosurg 2000;92:637-41.

5. Czinkota MR, Johnston WJ. Choosing a career and specialty: when do students decide? Health Care Manage Rev. 1983;8(4):43-51.

6. Benzil DL, Abosch A, Fermano I, et al. The future of neurosurgery: a white paper on the recruitment and retention of women in neurosurgery. J Neurosurg. 2008;109:378-86.

7. Bland KI, Isaacs G. Contemporary trends in student selection of medical specialties; the potential impact on general surgery. Arch Surg. 2002;137(3):259-67.

8. Perez-Cruet, M. It's time to try again: neurosurgical curriculum needed in medical schools. AANS Bull. 2001;10(4):28-9.

9. Eseonu, CI. Attracting top medical students to Neurosurgery. AANS Neurosurgeon. 2010;19(3):5-9.

10. Kerfoot BP, Nabha KS, Masser BA, McCullough DL. What makes a medical student avoid or enter a career in Urology? Results of an international survey. J Urol. 2005;174:1953-7.

11. Wright S, Wong A, Newill C. The impact of role models on medical students. J Gen Intern Med. 1997;12:53-6.

12. Brem H, Amundson E. Preparing Hopkins medical students for a career in academic neurosurgery. Surgery. 2003;134(3):414-5.

13. Allen JG, Weiss ES, Patel ND, et al. Inspiring medical students to pursue surgical careers: outcomes from our cardiothoracic surgery research program. Ann Thorac Surg. 2009;87(6):1816-9.

14. Woodrow SI, O'Kelly C, Hamstra SJ, Wallace MC. Unemployment in an underserviced specialty?: The need for co-ordinated workforce planning in Canadian Neurosurgery. Can J Neurol Sci. 2006;33:170-4.

15. Toyota BD. Canadian neurosurgical manpower: need for selfdetermination. Can J Neurol Sci. 2006;33:123-4. 